\title{
Effect of luteinizing hormone on follicle stimulating hormone-activated paracrine signalling in rat ovary
}

\author{
C.D.Smyth, F.Miró, C.M.Howles and S.G.Hillier ${ }^{2}$ \\ Reproductive Endocrinology Laboratory, University of Edinburgh \\ Centre for Reproductive Biology, 37 Chalmers Street, Edinburgh \\ EH3 9EW, UK and 'Ares Services SA, 15 bis Chemin des Mines, \\ CH 1211 Geneva 20, Switzerland \\ ${ }^{2}$ To whom correspondence should be addressẹed
}

'Pưre' follicle stimulating hormone (FSH) and lutẹinịzing hormone (LH) are expected shortly to become available for pharmaceutical use in the clinical setting. To test the contribution of $\mathrm{LH}$ to optimal ovarian responsiveness to FSH, 21-day-old hypophysectomized, immature, female rats received four s.c. injections of recombinant human LH (rhLH; total dose 1-10 IU) and/or rhFSH (total dose 30-72 IU) given at 12-hourly intervals. At $48 \mathrm{~h}$ after the first injection, ovaries were removed, weighed and used to isolate granulosa and thecal/interstitial cells for assessment of basal and gonadotrophin-responsive steroidogenesis in vitro, or homogenized to extract total RNA for Northern analysis of 17-hydroxylase/ $\mathrm{C}_{17-20}$-lyase (cytochrome $P$ $450_{\mathrm{cl} /}$ ) mRNA. Serum oestradiol and uterine weight were measured as indices of ovarian oestrogen production; androstenedione was measured to reflect ovarian androgen production. Consistent with the two-cell, two-gonadotrophin model of oestrogen synthesis, increased ovarian oestrogen secretion only occurred if both rhFSH and rhLH were given simultaneously. Treatment with rhFSH alone stimulated ovarian weight gain and granulosa cell aromatase activity without oestrogen secretion, whereas rhLH alone stimulated thecal androgen synthesis and androgen secretion. When the total rhLH dose was fixed at $1 \mathrm{IU}$, giving rise to an unmeasurably low serum concentration of rhLH, additional treatment with rhFSH (30-72 IU) dose-dependently stimulated serum androgen concentrations as well as oestrogen concentrations. The $\sim 2.0 \mathrm{~kb}$ sized $P-450_{\mathrm{cl} 7 \alpha}$ mRNA transcript was undetectable in the ovaries of untreated control animals but was abundant in the ovaries of positive controls treated with 15 IU of pregnant mare serum gonadotrophin. Treatment with 1 IU of rhLH alone barely induced a $P-450 \mathrm{cl} \alpha \alpha$ mRNA signal and treatment with 30 IU of rhFSH alone was completely ineffective. However, combined treatment with 1 IU of rhLH and 30 IU of rhFSH markedly enhanced the $P$ $450_{\mathrm{c} 17 \alpha}$ mRNA signal to a level approaching the positivecontrol. Since $\boldsymbol{P}-\mathbf{4 5 0} 0_{\mathrm{cl} / \alpha} \mathrm{mRNA}$ is expressed exclusively in thecal cells, which do not possess FSH receptors, we conclude that (i) rhFSH upregulates thecal $\boldsymbol{P}-\mathbf{4 5 0} \mathbf{c}_{\mathrm{c} 17 \alpha}$ mRNA and hence follicular androgen synthesis via granulosa-on- theca paracrine signalling, and (ii) tonic stimulation by rhLH is required to facilitate thecal responsiveness to this rhFSH-activated paracrine signal(s).

Key words: androgen/cytochrome $P-450_{\mathrm{cl} / \alpha} /$ follicle stimulating hormone/luteịnizing hormone/oestrogen

\section{Introduction}

Urinary follicle stimulating hormone (FSH) preparations lacking significant contamination with lụteinizing hormone (LH) can induçe pre-ovulatory follicular development with minimal increases in ovarian oestrogen secretion when given to patients with World Health Organization (WHO) type I anovulatory infertility whose endogenous LH levels are too low to measure (Couzinet et al., 1988; Shoham et al:, 1991). However, in patients with detectable endogenous LH, treatment with 'pure' FSH induces normal follicular maturation and oestrogen secretion (Shoham et al., 1994). This type of response usually occurs when FSH is given to stimulate multiple follicular development following pituitary desensitization with a gonadotrophin-releasing hormone (GnRH) agonist [e.g. in assisted reproduction procedures (Edelstein et al., 1990) or in patients with WHO type II anovulatory infertility (Sagle et al., 1991)].

It has been known for more than 50 years that both FSH and LH are necessary to stimulate pre-ovulatory follicular development and oestradiol synthesis (Fevold, 1941; Greep et al., 1942). According to the two-cell, two-gonadotrophin model of oestrogen synthesis (Armstrong and Dorrington, 1979), FSH acts on granulosa cells to induce aromatase (cytochrome $P-450_{\text {arom }}$ ) activity, while LH stimulates the formation of thecal androgens that serve as oestrogen precursors. Recently, we have demonstrated in vivo and in vitro that FSH-induced paracrine signals from granulosa cells also influence thecal androgen synthesis (Smyth et al., 1993, 1994). When pituitary-intact immature female rats were treated with recombinant human (rh) FSH, LH-responsive thecal/interstitial cell androgen synthesis in vitro was enhanced relative to cells from untreated controls. Expression of thecal/interstitial 17hydroxylase $/ \mathrm{C}_{17-20}$-lyase (cytochrome $P-450_{\mathrm{cl} 7 \alpha}$ ) mRNA was also markedly increased by FSH treatment in vivo. Since FSH receptors reside exclusively on granulosa cells, this result was interpreted as evidence of granulosa-to-theca paracrine signalling. However, the stimulatory effect of FSH treatment in vivo was lost if endogenous gonodotrophins were deleted by hypophysectomy. This suggested that tonic thecal stimulation by LH might be necessary for FSH-activated paracrine 
signalling to be manifest in vivo. Here we report experiments that directly confirm this hypothesis.

\section{Materials and methods}

\section{Human recombinant gonadotrophins}

The rhFSH was GONAL-F ${ }^{\mathrm{TM}}$ (Serono Laboratories UK Ltd, Welwyn Garden City, Herts, UK) with an in-vivo bioactivity of $13096 \mathrm{IU} \mathrm{FSH/mg} \mathrm{(rat} \mathrm{ovarian} \mathrm{weight} \mathrm{gain} \mathrm{assay).} \mathrm{The}$ rhLH (Serono) had an in-vivo bioactivity of $13108 \mathrm{IU} \mathrm{LH} / \mathrm{mg}$ (rat ventral prostate weight gain assay).

\section{Animals and experimental design}

In-vivo effects of rhFSH and rhLH were tested in female Wistar rats hypophysectomized at 21 days of age by the supplier (Charles River UK Ltd, Margate, Kent, UK). Gonadotrophin(s) was injected s.c. in $100 \mu \mathrm{l}$ of phosphate-buffered saline (PBS) containing $0.1 \%(\mathrm{w} / \mathrm{v})$ bovine serum albumin (BSA) (ICN Biochemicals, High Wycombe, Bucks, UK). Four 12-hourly injections were given starting at the age of 25 days. The treatments were rhFSH (total dose 30 or 72 IU/animal) and/or rhLH (total dose 1 or 10 IU/animal). Negative controls received injections of vehicle alone and positive controls received a single injection (15 IU) of pregnant mare serum gonadotrophin (PMSG; Sigma Chemicals Ltd, Poole, Dorset, UK). Each experimental and control treatment group contained at least five animals, and all experiments were done at least twice.

\section{Recovery of tissue and serum}

Approximately $12 \mathrm{~h}$ after the last injection ( $48 \mathrm{~h}$ after initiating treatment), animals were killed by carbon dioxide asphyxiation. The ovaries and uterus were removed, dissected free of fat and extraneous tissues and weighed on an electronic balance (Cahn TA 4100; Cahn, Cerritos, CA, USA). Ovaries were used to isolate thecal/interstitial cells and/or granulosa cells or immediately snap-frozen in liquid nitrogen for isolation of total RNA. Blood was sampled from the posterior vena cava and allowed to clot at room temperature for $30 \mathrm{~min}$. Serum was separated and stored at $-20^{\circ} \mathrm{C}$ for hormone assays.

\section{Isolation and culture of granulosa and thecal/interstitial cells}

Granulosa and thecal/interstitial cell preparations were prepared using previously described procedures (Miró et al., 1991; Magoffin and Erickson, 1982). Briefly, all visible follicles were first punctured using a 27-gauge hypodermic syringe needle to express granulosa cells into culture medium. The medium was M-199 (Gibco Ltd, Paisley, Renfrewshire, UK) containing Earle's salts, $25 \mathrm{mM}$ HEPES buffer, penicillin (50 $\mathrm{IU} / \mathrm{ml})$, streptomycin $(50 \mu \mathrm{g} / \mathrm{ml})$ and additional $(2.0 \mathrm{mM}) \mathrm{L}$ glutamine, supplemented with $0.1 \%(\mathrm{w} / \mathrm{v})$ BSA. Cells were then sedimented by centrifugation $(5 \mathrm{~min}$ at $800 \mathrm{~g}$ ), resuspended in fresh culture medium and counted in a haemocytometer. Cell viability, determined by staining with trypan blue, was consistently $>40 \%$.

After eliminating as many granulosa cells as possible, the residual ovarian tissue was rinsed in culture medium and enzymically digested by incubation for $30 \mathrm{~min}$ at $37^{\circ} \mathrm{C}$ in fresh medium containing $0.1 \%(\mathrm{w} / \mathrm{v})$ collagenase type II from Clostridium histolyticum (Sigma) and $0.01 \%$ DNase (Sigma). Complete dispersal into a single-cell suspension was achieved by repeated pipetting at the end of this incubation. The cells were sedimented by centrifugation $(5 \mathrm{~min}$ at $800 \mathrm{~g}$ ), resuspended in fresh culture medium containing $5.0 \%(\mathrm{v} / \mathrm{v})$ donor calf serum (Gibco) and counted in a haemocytometer. Cell viability, determined by staining with trypan blue, was consistently $>90 \%$.

Multiwell plastic culture dishes (Linbro Space Savers ${ }^{\mathrm{TM}}$ from Flow Laboratories, Rickmansworth, Herts, UK) were inoculated with replicate $0.5 \mathrm{ml}$ portions of granulosa or thecal cell suspensions ( 40000 cells) in culture medium. Thecal cells were preincubated in medium containing $5.0 \%$ donor calf serum to allow cell anchorage and recovery from the enzymic dispersal procedure. Incubation of thecal/interstitial cells did not measurably stimulate oestrogen production, which confirmed minimal contamination with granulosa cells. The preincubation was for $24 \mathrm{~h}$ at $37^{\circ} \mathrm{C}$ in a humidified atmosphere of $5 \% \mathrm{CO}_{2} / 95 \%$ air. After removing the serum-containing medium and washing the cell monolayers with $1 \mathrm{ml}$ of prewarmed $\left(37^{\circ} \mathrm{C}\right) \mathrm{PBS}$, each culture well received $0.5 \mathrm{ml}$ of serum-free medium with or without human LH (LER-1972; $5179 \mathrm{IU} \mathrm{LH} / \mathrm{mg}, 2.5 \mathrm{IU} \mathrm{FSH} / \mathrm{mg}$ ) at a concentration of $10 \mathrm{ng} /$ $\mathrm{ml}$. All treatments were done in triplicate.

Incubation was for $48 \mathrm{~h}$ at $37^{\circ} \mathrm{C}$, after which the medium was collected and stored frozen at $-20^{\circ} \mathrm{C}$ for subsequent analysis of androgen content by radioimmunoassay, as described below. The granulosa cells were incubated in $0.5 \mathrm{ml}$ of serum-free medium with or without human FSH (LER 8/ 116; $900 \mathrm{IU} \mathrm{FSH} / \mathrm{mg}, ~-0.5 \mathrm{IU} \mathrm{LH} / \mathrm{mg}$ ) at a concentration of $30 \mathrm{ng} / \mathrm{ml}$ and/or $1 \mu \mathrm{M}$ testosterone (Sigma). All treatments were done in triplicate. Incubation was for $48 \mathrm{~h}$ at $37^{\circ} \mathrm{C}$, after which the medium was collected and stored frozen at $-20^{\circ} \mathrm{C}$ for subsequent analysis of oestradiol content by radioimmunoassay, as described below.

\section{Androstenedione assay}

The amount of androstenedione in serum and spent culture medium was determined by radioimmunoassay (Hillier et al., 199lb). The androstenedione antiserum was rabbit anti-androst4-ene-3,17-dione-7 $\alpha$-carboxyethylthioether-BSA. Major crossreactions were androstenedione, $100 \%$; androsterone, $46.3 \%$; $5 \alpha$-androstane-3,17-dione, $50 \%$; testosterone, $37 \%$; and $<0.5 \%$ for all other steroids tested. The inter- and intra-assay precision was $<15 \%$ (coefficient of variation), with a sensitivity (minimum detectable dose) of $0.3 \mathrm{nmol} / 1$.

\section{Oestradiol assay}

The amount of oestradiol in serum and spent culture medium was determined by radioimmunoassay (Hillier et al., 1981). The oestradiol antiserum was donkey $\mathrm{K}_{3}$ anti-oestradiol-17hemisuccinyl-BSA (provided by Dr G.Read, Tenovus Institute, Cardiff, UK). Major cross-reactions were oestradiol-17 $\beta$, $100 \%$; oestrone, $<10 \%$; and $<0.5 \%$ for all other steroids tested. The inter- and intra-assay precision was $<15 \%$ (coefficient of vaiation), with a sensitivity of $0.2 \mathrm{nmol} / \mathrm{l}$. 


\section{FSH and LH assays}

rhFSH and rhLH in hypophysectomized rat serum were measured by specific immunoradiometric assays (Serono FSH MAIAclone $^{T M}$ and Serono LH MAIAclone ${ }^{T M}$ supplied by Intereset, Wokingham, Berks, UK). Assay sensitivities were $0.25 \mathrm{mIU} \mathrm{FSH} / \mathrm{ml}$ and $0.15 \mathrm{mIU} \mathrm{LH} / \mathrm{ml}$. Serum samples were analysed as a single batch with an intra-assay precision of $\sim 3 \%$.

\section{Northern analysis of cytochrome $P-450_{c 17 \alpha} m R N A$}

Frozen tissue (whole ovaries) was homogenized in an ice-cold solution containing $4 \mathrm{M}$ guanidium thiocyanate, $24 \mathrm{mM}$ sodium citrate, $0.5 \%(\mathrm{w} / \mathrm{v})$ sarcosyl and $0.1 \mathrm{M} \beta$-mercaptoethanol (all from Sigma). Total RNA was extracted with phenolchloroform (Chomczynski and Sacchi, 1987) and size-fractionated by electrophoresis in $1.2 \%$ agarose gels containing $2.2 \mathrm{M}$ formaldehyde. RNA molecular weight markers (Gibco) were run alongside samples on each gel and ethidium bromide staining was used to check the uniformity of sample loading. RNA was transferred onto nylon membranes (Hybond-N; Amersham International, Aylesbury, Bucks, UK) in $20 \times$ sodium citrate/sodium chloride (SSC), by capillary blotting. cDNA probe to rat $P-450_{\mathrm{cl} 7 \alpha}$ mRNA (full-length cytochrome $P-450_{\mathrm{cl} 17 \alpha}$; generously donated by Dr J. Ian Mason) (Fevold et al., 1989) was labelled with [ $\left.{ }^{32} \mathrm{P}\right] \mathrm{dCTP}$ by random priming (Megaprime kit; Amersham). Prehybridization was carried out for $1-2 \mathrm{~h}$ at $42^{\circ} \mathrm{C}$ in $5 \times$ saline/sodium phosphate/EDTA (SSPE), $5 \times$ Denhardt's solution, $18.5 \%(\mathrm{v} / \mathrm{v})$ formamide and $0.5 \%(\mathrm{w} / \mathrm{v})$ sodium dodecyl sulphate (SDS). Hybridization was carried out overnight in the same buffer containing $\sim 1 \times 10^{6}$ $\mathrm{cpm} / \mathrm{ml}$ of probe. The membranes were then washed at $65^{\circ} \mathrm{C}$ for $\sim 1 \mathrm{~h}$ in each of three different solutions containing $1 \%$ SDS and decreasing salt concentrations $(2 \times, 1 \times$ and $0.5 \times$ SSC). The membranes were then exposed to Kodak XAR-5 for 1-3 days at $-70^{\circ} \mathrm{C}$ using an intensifying screen.

\section{Statistics}

Analysis of variance with the Newman-Keuls test was used to analyse differences between experimental and control observations. Differences assigned a $P$ value of $<0.05$ were regarded as statistically significant.

\section{Results}

Effect of rhFSH and rhLH administration in vivo on serum hormone concentrations

Serum FSH, LH, oestradiol and androstenedione concentrations in hypophysectomized immature female rats treated with rhFSH and/or rhLH are shown in Figure 1. The circulating FSH concentration following $48 \mathrm{~h}$ of treatment increased to $350-400$ IU/l following 72 IU of rhFSH (Figure la). At 1 IU of rhLH, serum $\mathrm{LH}$ remained undetectable but at $10 \mathrm{IU}$ of rhLH, it rose to $\sim 17 \mathrm{IU} / \mathrm{l}$ (Figure lb). Serum oestradiol was unmeasurable if either rhFSH or rhLH was given alone. However, when given in combination each gonadotrophin dose-dependently increased oestradiol (Figure lc). Serum androstenedione was increased dose-dependently by rhLH alone (Figure ld). Treatment with $30 \mathrm{IU}$ of $\mathrm{rhFSH}$ alone did not
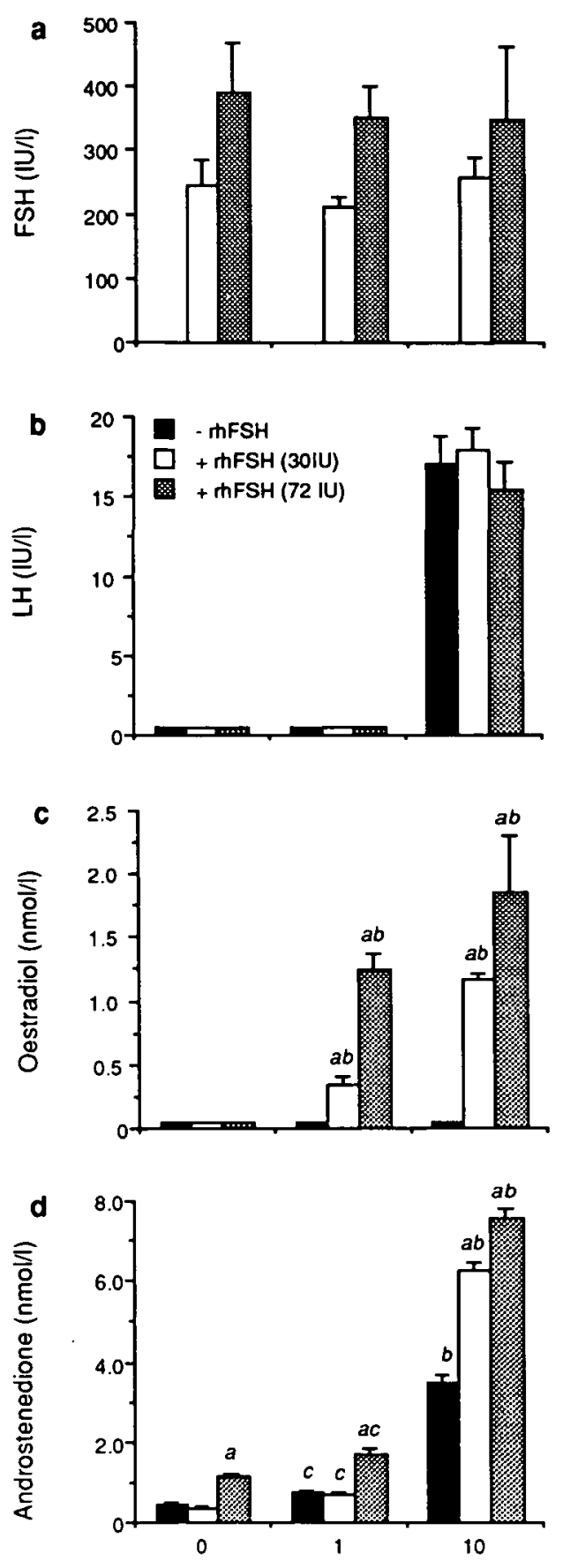

rh-LH (IU)

Fig. 1. Effect of treatment with recombinant human follicle stimulating hormone (rhFSH) and/or recombinant human luteinizing hormone (rhLH) in vivo on plasma concentrations of (a) rhFSH, (b) rhLH, (c) oestradiol and (d) androstenedione. Hypophysectomized immature female rats were treated with vehicle alone or rhFSH (total dose 30-72 IU) and/or rhLH (total dose 1-10 IU) given as four 12-hourly s.c. injections. At $48 \mathrm{~h}$ after beginning treatment, the animals were killed and blood was sampled from the posterior vena cava and analysed by specific immunoradiometric assay (rhFSH and $\mathrm{rhLH}$ ) or specific radioimmunoassay (oestradiol and androstenedione). Results from a representative experiment are expressed as mean $\pm \mathrm{SE}(n \geqslant 5)$. Statistics: $a$ denotes significant $(P<0.01)$ effect due to rhFSH treatment versus corresponding treatment without $\operatorname{rhFSH} ; b(P<0.01)$ and $c(P<0.05)$ denote significant increase due to rhLH versus corresponding treatment without rhLH. 
stimulate androstenedione, but at $72 \mathrm{IU}$ rhFSH increased androstenedione on average 2- to 3-fold relative to control. The lower dose of rhFSH had no effect on the androstenedione response to $1 \mathrm{IU}$ of $\mathrm{hLH}$ but increased the response to $10 \mathrm{IU}$ rhLH $\sim 2$-fold; 72 IU of rhFSH increased the androstenedione responses to both 1 and $10 \mathrm{IU}$ rhLH by a similar magnitude (Figure 1d).

\section{Effect of rhFSH and rhLH administration in vivo on ovarian and uterine weights}

Ovarian and uterine weights following treatment with a fixed dose (30 IU) of $20 \mathrm{rhFSH}$ in the presence of 1 and $10 \mathrm{IU}$
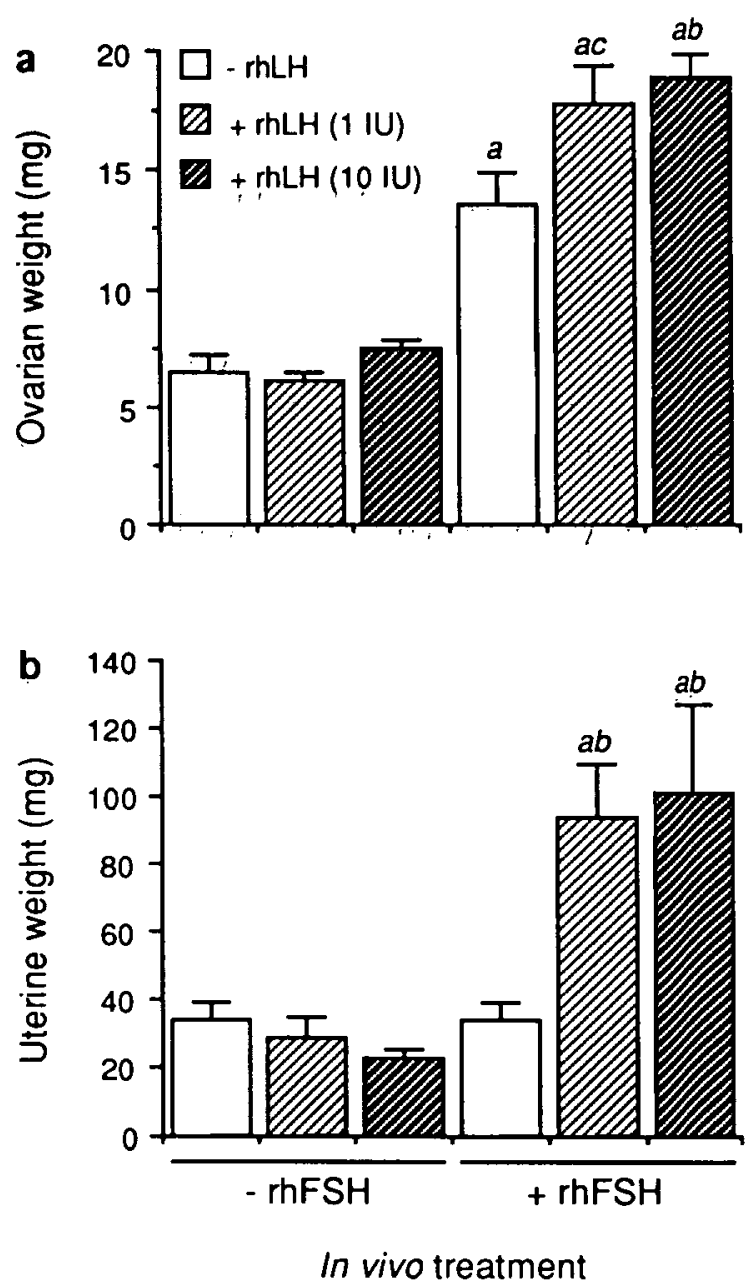

Fig. 2. Effect of treatment with recombinant human follicle stimulating hormone (rhFSH) and/or recombinant human luteinizing hormone (rhLH) in vivo on (a) ovarian and (b) uterine weights. Hypophysectomized immature female rats were treated with vehicle alone or vehicle containing rhFSH (total dose $30 \mathrm{IU}$ ) and/or rhLH (total dose 1-10 IU) given as four 12-hourly s.c. injections. At $48 \mathrm{~h}$ after beginning treatment the animals were killed and the ovaries and uteri were immediately removed and cleaned of all extraneous material before weighing. Results from a representative experiment are expressed as weight \pm SE of a single ovary $(n \geqslant 10)$, or weight \pm SE of uterine horn $(n \geqslant 5)$. Statistics: $a$ denotes a significant $(P<0.01)$ increase due to rhFSH treatment versus corresponding treatment without rhFSH; $b(P<0.01)$ and $c(P<$ $0.05)$ denote significant increase due to rhLH treatment versus corresponding treatment without rhLH.
rhLH are shown in Figure 2. Neither dose of rhLH alone significantly affected ovarian weight. However, rhFSH alone increased ovarian weight $\sim 2$-fold, and this response was further enhanced by combining rhFSH treatment with either dose of rhLH (Figure 2a). Alone, neither gonadotrophin significantly affected uterine weight, whereas both combinations of rhLH with rhFSH were stimulatory (Figure 2b). Use of 72 IU of rhFSH instead of 30 IU of rhFSH caused even greater increases in ovarian weight, without significantly affecting uterine weight unless rhLH was also present (data not shown).

\section{Effect of rhFSH and rhLH administration in vivo on granu- losa cell aromatase activity in vitro}

Treatment with rhFSH strongly stimulated granulosa cell aromatase activity both in vivo and in vitro (Figure 3 ). The aromatase response to combined treatment with rhFSH (30 IU) and rhLH (1 IU) was comparable with that of rhFSH alone. Treatment with $1 \mathrm{IU}$ of rhLH alone was ineffective.

\section{Effect of rhFSH and rhLH administration in vivo on thecal/ interstitial cell androgen production in vitro}

In-vivo treatment with rhFSH (30 IU) or rhLH (1 IU) alone had no significant effect on basal or LH-responsive thecal/ interstitial cell androgen production in vitro, whereas combined treatment with the same doses of rhFSH and rhLH in vivo led to a markedly enhanced androstenedione response to $\mathrm{LH}$ in vitro (Figure 4).

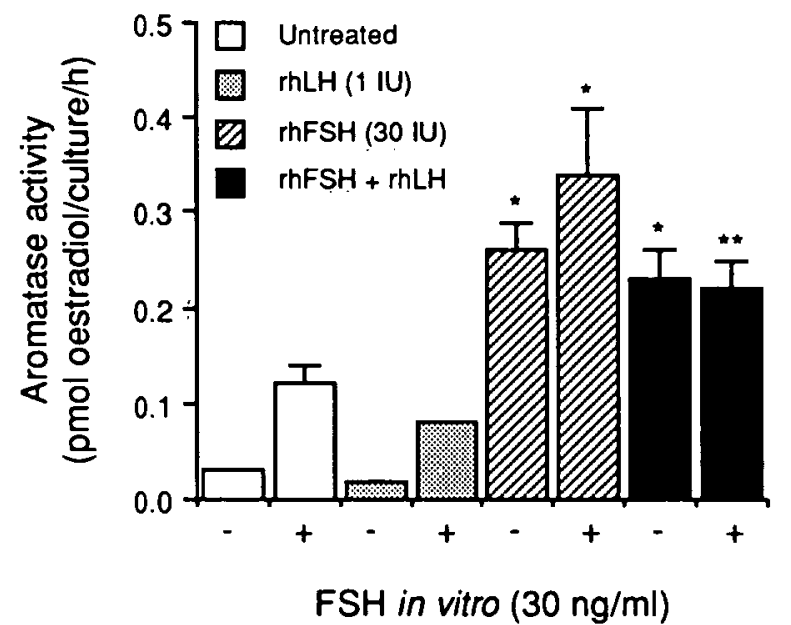

Fig. 3. Effect of treatment with recombinant human follicle stimulating hormone (rhFSH) and/or recombinant human luteinizing hormone ( $\mathrm{hLH}$ ) in vivo on granulosa cell aromatase activity. Hypophysectomized female rats were treated with vehicle alone or vehicle containing rhFSH (total dose $30 \mathrm{IU}$ ) and/or rhLH (total dose $1 \mathrm{IU}$ ) given as four 12-30-hourly s.c. injections. At $48 \mathrm{~h}$ after beginning treatment the animals were killed and ovaries removed for isolation of granulosa cells. Granulosa cell cultures (40000 viable cells per well) were incubated for $48 \mathrm{~h}$ in serum-free medium with $1.0 \mu \mathrm{M}$ testosterone (aromatase substrate) in the presence or absence of rhFSH $(30 \mathrm{ng} / \mathrm{ml})$. Oestradiol in the spent culture medium was determined by radioimmunoassay. Results from a representative experiment are expressed as pmol of oestradiol produced/1000 cells/h $\pm \operatorname{SE}(n=3)$. Asterisks denote a significant difference due to rhFSH treatment in vivo versus the corresponding untreated control $\left({ }^{*} P<0.01 ;{ }^{* *} P<0.05\right)$. 
Effect of FSH and LH administration in vivo on ovarian P450 ${ }_{c l 7 \alpha}$ mRNA expression

A $P-450_{\mathrm{c} 17 \alpha}$ mRNA signal was not detectable by Northern analysis of ovarian total RNA from vehicle-treated control animals (Figure 5). However, treatment with PMSG as a positive control induced an abundant $\sim 2.0 \mathrm{~kb}$-sized transcript. Treatment with rhLH (1 IU) alone barely stimulated the appearance of this transcript, and rhFSH (30 IU) alone was completely negative. However, in the presence of LH, FSH strongly increased the intensity of the $P-450_{\mathrm{cl} \alpha}$ mRNA signal.

\section{Discussion}

This study using recombinant (hence 'pure') humari gonadotrophins confirms that both FSH and LH are necessary for follicular oestrogen synthesis (Fevold, 1941; Greep et al., 1942; Armstrong and Dorrington, 1979; Mannaerts et al., 1991). FSH treatment alone stimulates follicular growth and increased expression of granulosa cell $P-450_{\text {arom }}$ (Fitzpatrick and Richards, 1991; Whitelaw et al.; 1992), while LH acts directly to stimulate $P-450_{c 17 \alpha}$ in the theca interna (Fortune and Armstrong, 1977; Smyth et al., 1993). Thereby the two gonadotrophins jointly regulate oestrogen synthesis.

A novelty here is that we have used recombinant human gonadotrophins and hypophysectomized animals to dissect out a paracrine (granulosa on theca) interaction that is activated by FSH and facilitated by LH. The ovarian weight, serum

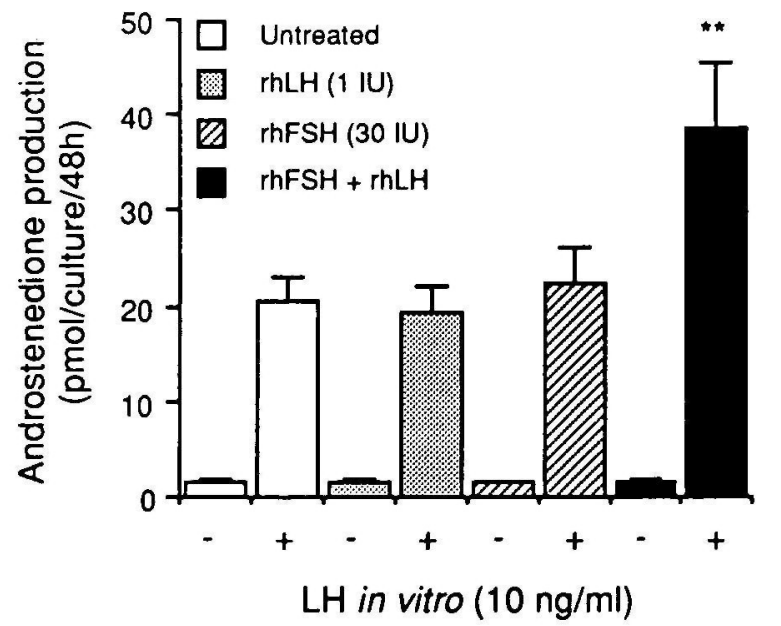

Fig. 4. Effect of recombinant human follicle stimulating hormone (rhFSH) and/or recombinant human luteinizing hormone (rhLH) administration in vivo on thecal/interstitial cell androgen production in vitro. Hypophysectomized female rats were treated with vehicle alone or vehicle containing rhFSH (total dose $30 \mathrm{IU}$ ) and/or rhLH (total dose I IU) given as four 12-hourly s.c. injections. At $48 \mathrm{~h}$ after beginning treatment the animals were killed and ovaries removed for isolation of thecal/interstitial cells. The thecal/ interstitial cell cultures ( 40000 viable cells per culture well) were incubated for $48 \mathrm{~h}$ in serum-free medium with and without hLH $(10 \mathrm{ng} / \mathrm{ml})$. Androstenedione in the spent culture medium was determined by radioimmunoassay. Results from a representative experiment are expressed as pmol androstenedione produced/ culture/48 h $\pm \mathrm{SE}(n=3)$. Asterisks denote significant $(P<0.01)$ difference in response to $\mathrm{LH}$ in vitro versus any other response to $\mathrm{LH}$ in vitro. oestrogen/uterine weight and aromatase activity data presented here are all consistent with previously reported actions of rhFSH on ovarian oestrogen synthesis in vivo and in vitro (Mannaerts et al., 1991; Whitelaw et al., 1992). rhFSH potently stimulates ovarian weight (i.e. follicular growth) and granulosa cell aromatase activity, but oestrogen secretion (uterine weight gain) only occurs when LH activity is also given. rhLH alone does not cause ovarian weight gain or oestrogen secretion but does increase androgen secretion. Importantly, treatment with rhFSH (devoid of LH activity, and hence unable to act directly on thecal cells) dose-dependently increases the androgenic response to rhLH. Since granulosa cells are the only cells in the female body known to possess FSH receptors, this evidence strongly suggests that FSH is able to activate a granulosaderived paracrine signal(s) that positively regulates thecal androgen synthesis. Moreover, direct stimulation with rhLH sensitizes the theca interna to this FSH-induced paracrine signal.

Unequivocal evidence that rhLH promotes thecal/interstitial responsiveness to rhFSH in vivo is provided by the demonstration that ovarian $P-450_{\mathrm{cl} 17 \alpha}$ mRNA, shown previously to be

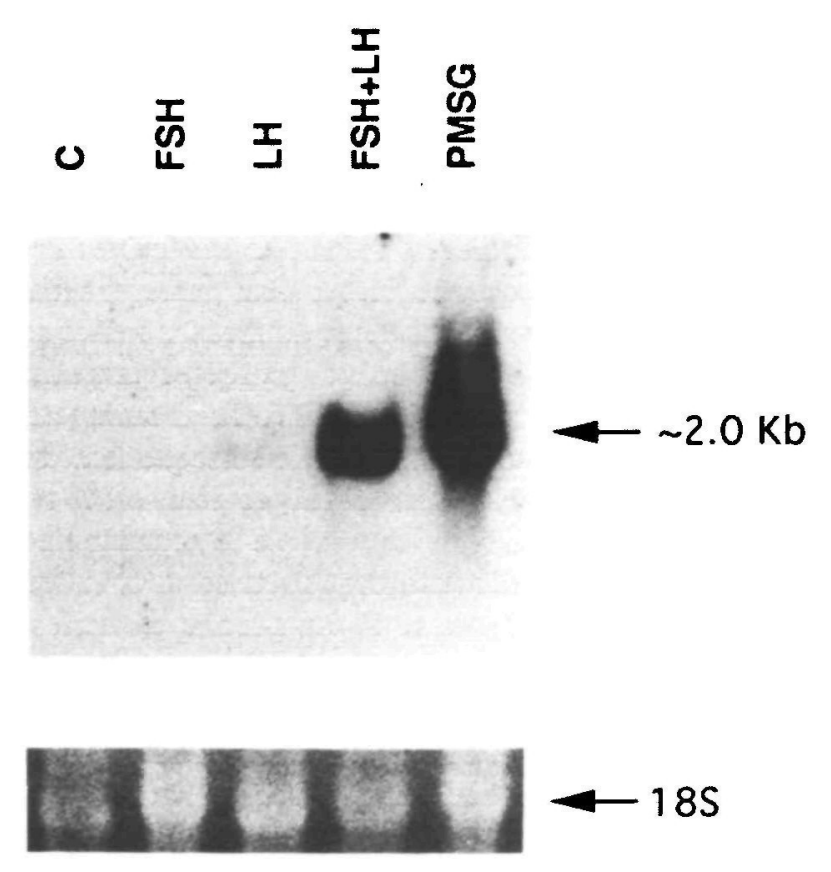

Fig. 5. Effect of recombinant human follicle stimulating hormone (rhFSH) and/or recombinant human luteinizing hormone (rhLH) administration in vivo on ovarian cytochrome $P-450_{\mathrm{cl} 7 \alpha} \mathrm{mRNA}$ expression in hypophysectomized female rats. The animals received four 12-hourly s.c. injections of rhFSH (total dose $30 \mathrm{IU}$ ) and/or rhLH (total dose $1 \mathrm{IU}$ ); negative controls received injection vehicle alone; positive controls received a single injection (15 IU) of pregnant mare serum gonadotrophin. Ovaries were removed $48 \mathrm{~h}$ after the first injection. Total ovarian RNA was size-fractionated ( $20 \mu \mathrm{g} /$ track) by electrophoresis on a $1.2 \%$ agarose-formaldehyde gel and blotted onto a nylon membrane. Upper panel: Northern analysis using a ${ }^{32} \mathrm{P}$-labelled (random priming) bovine cytochrome $P-450_{\text {cl7 } \alpha}$ cDNA. Exposure of the autoradiogram to Kodak XAR-5 film was for 3 days at $-70^{\circ} \mathrm{C}$ using an intensifying screen. The -2.0 kb-sized cytochrome $P-450_{\mathrm{cl} 7 \alpha}$ transcript is indicated. Lower panel: Ethidium bromide-stained 18S rRNA, illustrating sample loading. 
located exclusively in thecal/interstitial cells (Smyth et al., 1993), is only measurably increased by treatment with rhFSH if rhLH is given concurrently. Significantly, the dose of rhLH required to elicit this effect in hypohysectomized immature female rats is so low ( $1 \mathrm{IU}$ of rhLH over $48 \mathrm{~h}$ ) that it is not even detectable in blood using a sensitive immunoradiometric assay for human $\mathrm{LH}$.

The nature of the paracrine signal activated by $\mathrm{FSH}$ is presently unknown. However, both IGF-I (Adashi et al., 1985) and inhibin (Hsueh et al., 1987) of granulosa cell origin are obvious possibilities. We have previously shown that gonadotrophin-induced oestradiol biosynthesis in individually cultured rat follicles can be blocked by the presence of a neutralizing antibody to inhibin (Smyth et $a l ., 1994)$. Moreover, inhibin antibody-induced blockade of oestrogen synthesis is overcome by the presence of exogenous aromatase substrate (androstenedione) in the culture medium. This strongly implicates inhibin in the paracrine mediation of FSH action on thecal androgen synthesis in the rat ovary. Since FSH also stimulates inhibin production by human granulosa cells (Hillier et al., 1991a) and inhibin promotes LH-stimulated androgen synthesis by human thecal cells (Hillier et al., 1991b), the implications of the present results for human reproductive physiology seem obvious.

It is known from previous studies of $\mathrm{LH}$ action on gonadal cells that $<1 \%$ of $\mathrm{LH}$ receptors need to be occupied to elicit maximal steroidogenic responses in vitro (Catt and Dufau, 1977). The present demonstration that unmeasurably low, endogenous concentrations of $\mathrm{LH}$ are sufficient to facilitate FSH-responsive ovarian androgen synthesis further emphasizes the minimal, albeit crucial, dependence that the ovary has on LH to undertake apparently normal rates of follicular oestrogen synthesis.

These experimental results could have potential clinical relevance. If they can be extrapolated to humans, they offer a means to interpret the effects of 'pure' FSH preparations when used to stimulate ovarian function in women with various types of infertility, as follows.

(i) Using FSH alone in conjunction with $\mathrm{GnRH}$-agonist suppression of pituitary function to stimulate multiple follicular development so that eggs can be collected for assisted reproduction procedures. Repeated exposure of pituitary gonadotropes to GnRH-agonists causes 'down-regulation' involving microaggregation of $\mathrm{GnRH}$ receptors and internalization of agonist - receptor complexes, such that LH and FSH concentrations in blood fall to near undetectable amounts. Despite a dearth of endogenous LH, administration of 'pure' FSH alone usually stimulates multiple follicular development and oestrogen secretion to degrees comparable with those achieved when FSH and LH (i.e. human menopausal gonadotrophin) are given simultaneously. If FSH activates a paracrine mechanism that up-regulates LH-responsive androgen synthesis, and hence oestradiol synthesis, it becomes evident why FSH is effective in spite of the minimal $\mathrm{LH}$ concentrations present when routine GnRH-agonist regimens are employed. It also follows that long-term or 'deep' pituitary suppression could make patients less responsive to $\mathrm{FSH}$.

(ii) Patients with WHO group II type infertility. Women with anovulatory infertility but who are not devoid of endogenous $\mathrm{LH}$ often receive ovulation induction therapy, with or without pituitary down-regulation. Such patients frequently overrespond to FSH therapy and, if care is not taken, they can develop ovarian hyperstimulation. Many of these women have polycystic ovaries (PCO) associated with high basal serum LH concentrations. Thecal cells from PCO follicles undertake higher rates of androgen synthesis than those of 'normal' follicles of a similar size (Gilling-Smith et al., 1993). Since androgens enhance FSH-stimulated granulosa cell function (including inhibin production) in vitro (Hillier et al., 1991a), and inhibin and/or other granulosa cell factors have the potential to promote LH-responsive thecal androgen synthesis (Hillier et al., 1991b), reciprocal paracrine signalling between LH-stimulated thecal cells and FSH-stimulated granulosa cells could bring about follicular hypersensitivity to FSH.

(iii) Patients suffering from a complete LH deficiency (i.e. WHO group I type infertility). When such patients are given ovarian stimulation therapy, the usual aim is to induce monovulation so that conception can occur in'vivo. A normal pattern of oestrogen production is integral to a successful therapeutic outcome. An adeqate ovarian response to 'pure' FSH therefore requires simultaneous administration of $\mathrm{LH}$, either at doses that stimulate thecal androgen synthesis directly or in reduced amounts sufficient to promote the indirect responsiveness of thecal cells to FSH demonstrated here.

\section{Acknowledgements}

We thank Dr J. Ian Mason (Cecil H. and Ida Green Center for Reproductive Biology Sciences, University of Texas Southwestern Medical Center, Dallas, TX, USA) for providing the P-450 $0_{\mathrm{cl} / \alpha} \mathrm{cDNA}$ and Dr L.E. Reichert, Jr (Albany Medical College, Albany, NY, USA) for providing the human pituitary gonadotrophin preparations. Supported by the UK Medical Research Council (Programme Grant no. 8929853 )

\section{References}

Adashi,E.Y., Resnick,C.E., D'Ercole,A.J., Svododa,M.E. and Van Wyk,J.J. (1985) Insulin-like growth factors as intraovarian regulators of granulosa cell growth and function. Endocr. Rev., 6, $400-420$.

Armstrong,D.T. and Dorrington,J.H. (1979) Estrogen biosynthesis in the ovaries and testes. In Thomas,J.A. and Singhal,R.L. (eds), Regulatory Mechanisms Affecting Gonadal Hormone Action, Vol. 2. University Park Press, Baltimore, pp. 217-258.

Catt,K.J. and Dufau,M.L. (1977) Spare receptors in rat testes. Nature, 244, 219-222.

Chomczynski,P. and Sacchi,N. (1987) Single-step method of RNA isolation by acid guanidium thiocyanate-phenol-chloroform extraction. Anal. Biochem., 162, 156-159.

Couzinet,B., Lestrat,N., Brailly,S., Forest,M. and Schaison,G. (1988) Stimulation of ovarian follicular maturation with pure folliclestimulating hormone in women with gonadotrophin deficiency. J. Clin. Endocrinol. Metab., 66, 552-556.

Edelstein,M.C., Simonetti,S., Brzyski,R.G., Muasher,S.J. and Jones,G.S. (1990) Equivalency of human menopausal gonadotropin and follicle-stimulating hormone stimulation after gonadotropinreleasing hormone agonist suppression. Fertil. Steril., 53, 103-106. 
Fevold,H.L. (1941) Synergism of the follicle stimulating and luteinizing hormones in producing estrogen secretion. Endocrinology, 28, 33-36.

Fevold,H.R., Lorence,M.C., McCarthy,J.L., Trant,J.M., Kagimoto,M., Waterman,M.R. and Mason,J.I. (1989) Rat P45017 $\alpha$ from testis: characterisation of a full-length cDNA encoding a unique steroid hydroxylase capable of catalysing both $\Delta^{4}$ - and $\Delta^{5}$-steroid-17,20lyase reactions. Mol. Endocrinol., 3, 968-975.

Fitzpatrick,S.L. and Richards,J.S. (1991) Regulation of cytochrome P450 aromatase messenger ribonucleic acid and activity by steroids and gonadotropins in rat granulosa cells. Endocrinology, 129, $1452-1462$

Fortune,J.E. and Armstrong,D.T. (1977) Androgen production by theca and granulosa isolated from proestrus rat follicles. Endocrinology, 100, 1341-1347.

Gilling-Smith,C., Willis,D.S., Mason,H.D. and Franks,S. (1993) Increased androstenedione production by theca from polycystic ovaries. J. Endocr. (Suppl.), 137, OC 10.

Greep,R.O., van Dyke,H.B. and Chow,B.F. (1942) Gonadotropins of the swine pituitary I. Various biological effects of purified thylakentrin (FSH) and pure metakentrin (ICSH). Endocrinology, 30, 635-649.

Hillier,S.G., Reichert,L.E., Jr and Van Hall,E.V. (1981) Control of preovulatory follicular estrogen biosynthesis in the human ovary. J. Clin. Endocrinol. Metab., 52, 847-856.

Hillier,S.G., Wickings,E.J., Illingworth,P.J., Yong,E.L., Reichert,L.E., Baird,D.T. and McNeilly,A.S. (1991a) Control of immunoactive inhibin production by human granulosa cells. Clin. Endocrinol., 35, 71-78.

Hillier,S.G., Yong,E.L., Illingworth,P.J., Baird,D.T., Schwall,R.H. and Mason,A.J. (199lb) Effect of recombinant inhibin on androgen synthesis in cultured human thecal cells. Mol. Cell. Endocrinol., 75, R1-R6.

Hsueh,A.J.W., Dahl,K.D., Vaughan,J., Tucker,E., Rivier,J., Bardin,C.W. and Vale,W. (1987) Heterodimers and homodimers of inhibin subunits have different paracrine actions in the modulation of luteinizing hormone-stimulated androgen biosynthesis. Proc. Natl. Acad. Sci. USA, 84, 5082-5086.

Magoffin,D.A. and Erickson,G.F. (1982) Primary culture of differentiating ovarian androgen-producing cells in defined medium. J. Biol. Chem., 257, 4507-4513.

Mannaerts,B., De Leeuw,R., Geelen,J., Van Ravestein,A., Van Wezenbeek,P., Schuurs,A. and Kloosterboer,H. (1991) Comparative in vitro and in vivo studies on the biological characteristics of recombinant human follicle-stimulating hormone. Endocrinology, $129,2623-2630$.

Miró,F., Smyth,C.D. and Hillier,S.G. (1991) Development-related effects of recombinant activin on steroid synthesis in rat granulosa cells. Endocrinology, 129, 3388-3394.

Sagle,M.A., Hamilton-Fairley,D., Kiddy,D.S. and Franks,S. (1991) A comparative randomized study of low-dose human menopausal gonadotropin and follicle-stimulating hormone in women with polycyctic ovary syndrome. Fertil. Steril., 55, 56-60.

Schoot,D.C., Coelingh-Bennink,H.J.T., Mannaerts,B.M.J.L., Lamberts, S.W.J., Bouchard,P. and Fauser,B.C.J.M. (1992) Human recombinant follicle-stimulating hormone induces growth of preovulatory follicles without concomitant increase in androgen and estrogen biosynthesis in a woman with isolated gonadotropin deficiency. J. Clin. Endocrinol. Metab., 74, 1471-1473.

Shoham,Z., Balen,A., Patel,A. and Jacobs,H.S. (1991) Results of ovulation induction using human menopausal gonadotropin or purified follicle-stimulating hormone in hypogonadotropic hypogonadism patients. Fertil. Steril., 56, 1048-1053.

Shoham,Z., Howles,C.M., Zalel,Y., Weissman,A. and Insler,V. (1994) Induction of follicular growth and production of a normal hormonal milieu in spite of using a constant low dose of luteinizing hormone in women with hypogonadotrophic hypogonadism. Hum. Reprod., 9, $431-436$.

Smyth,C.D., Miró,F., Whitelaw,P.F., Howles,C.M. and Hillier,S.G. (1993) Ovarian thecal/interstitial androgen synthesis is enhanced by a follicle-stimulating hormone-stimulated paracrine mechanism. Endocrinology, 133, 1532-1538.

Smyth,C.D., Gosden,R.G., McNeilly,A.S. and Hillier,S.G. (1994) Effect of inhibin immunoneutralisation on steroidogenesis in rat ovarian follicles in vitro. J. Endocrinol., 140, 437-443; Corrigendum, 143, 407-409.

Whitelaw,P.F., Smyth,C.D., Howles,C.M. and Hillier,S.G. (1992) Cellspecific expression of aromatase and LH receptor mRNAs in rat ovary. J. Mol. Endocrinol., 9, 309-312.

Received on May 19, 1994; accepted on August 30, 1994 